\title{
Cord bilirubin as a Predictor of Neonatal Hyper bilirubinemia in healthy term babies
}

\author{
Rajput G. ${ }^{1}$, Dhanawade S. ${ }^{2}$ \\ ${ }^{1}$ Dr. Gouri Rajput. Resident, ${ }^{2}$ Dr. Sara Dhanawade. Professor, both are affiliated with Department of Pediatrics, Bharati \\ Vidyapeeth Deemed University Medical College \& Hospital, Sangli, Maharashtra, India.
}

Corresponding Author: Dr. Sara Dhanawade, Professor, Department of Pediatrics, Bharati Vidyapeeth Deemed University Medical College \& Hospital, Sangli. E-mail: drgourirajput@gmail.com

\begin{abstract}
Objectives: To assess the value of cord blood bilirubin in identifying term healthy babies who develop significant hyperbilirubinemia. Methodology: This Prospective cohort study, conducted from May 2016 to September 2016 in a tertiary care hospital included 100 term healthy breastfed babies without Rh incompatibility or significant illness. Cord bilirubin was estimated in all babies. Neonates were followed up daily for 5 days for hyperbilirubinemia. Serum bilirubin levels were estimated on day 5 in all babies. Significant hyperbilirubinemia was defined as bilirubin $>15 \mathrm{mg} / \mathrm{dl}$ after 72 hours. Results: Mean cord bilirubin was $2.8+2.4 \mathrm{mg} / \mathrm{dl}$ in those who developed hyperbilirubinemia and $2.5+2.91 \mathrm{mg} / \mathrm{dl}$ in those who did not.Clinically detectable jaundice was present in $72 \%$. Twenty-two percent babies developed hyperbilirubinemia. Peak serum bilirubin of babies who developed significant hyperbilirubinemia was $23+2.8 \mathrm{mg} / \mathrm{dl}$ at 120 hours. Cord bilirubin of $>2 \mathrm{mg} / \mathrm{dl}$ was present in 64 babies and 19 (29\%) developed hyper bilirubinemia. Cord bilirubin $<2 \mathrm{mg}$ was present in 36 and only $3(8 \%)$ developed hyper bilirubinemia $(\mathrm{p}=0.018)$. The sensitivity was $86 \%$ specificity was $40 \%$, positive predictive value was $29 \%$ and negative predictive valuewas $91 \%$ at critical cord bilirubin value of $>2 \mathrm{mg} / \mathrm{dl}$. ABO incompatibility was significantly associated with hyperbilirubinemia $(\mathrm{p}=0.0006)$ Conclusion: Cord bilirubin can be a good predictor of hyperbilirubinemia. Neonates with cord bilirubin $<2 \mathrm{mg} / \mathrm{dl}$ are probably safe for early discharge and those with bilirubin levels $>2 \mathrm{mg} / \mathrm{dl}$ need close follow up.
\end{abstract}

Keywords: Significant hyperbilirubinemia, Cordbilirubin, Healthy term babies, Predictor

\section{Introduction}

Clinical jaundice is seen in $60-70 \%$ of term and about $80 \%$ of preterm newborns [1]. Various methods have been suggested for prediction of neonatal jaundice such as physical examination, evaluation using risk factor table, routine predischarge transcutaneous bilirubin measurement and measuring expiratory carbon monoxidelevels. Neonatal hyperbilirubinemia if not treated in time, may cause bilirubin induced neurological dysfunction, kernicterus [2].

American Academic of Pediatrics (AAP) recommends that newborns discharged within 48 hours should have a follow-up visit after 48 to 72 hours for any significant jaundice or other problems [3]. This is not possible in India due to limited follow-up facilities. Financial constraints, family and traditional beliefs have led to early discharge of healthy term neonates after delivery

\footnotetext{
Manuscript received: $16^{\text {th }}$ March 2018

Reviewed: $25^{\text {th }}$ March 2018

Author Corrected: $31^{\text {st }}$ March 2018

Accepted for Publication: $4^{\text {th }}$ April 2018
}

[4,5]. The concept of prediction of jaundice using cord bilirubin has been studied by various investigators, but the results have been inconsistent $[6,7,8,9]$. There is a need for identifying healthy term babies at birth who may develop significant hyperbilirubinemia in order to implement early treatment and minimize the risk of bilirubin associated brain damage [7]. This study was aimed at evaluating the usefulness of cord bilirubin as a predictor of neonatal hyper bilirubinemia in healthy term babies.

\section{Materials \& Methods}

Objective: To assess the value of cord blood bilirubin in identifying healthy term babies who developed subsequent hyperbilirubinemia.

Study design: Prospective study.

Stud area: The study was conducted in post-natal ward of a tertiary care teachinghospital in western Maharashtra. 
Study period: 1st may 2016 to September 2016 (6 months)

Study population: Healthy term babies ( $>37$ weeks) deliveredat our hospital.

Inclusion criteria: Healthy terms babies (Gestational age $>37$ weeks) and APGAR score of over 7 at first and fifth minute of life.

Exclusion criteria: The babies with significant morbidities that could aggravate hyperbilirubinemia, Rhincompatibility and APGAR score $<7$ at one minute were excluded.

Methodology: Informed written consent was obtained from parents. Bilirubin estimations were done using DIAZO method in the biochemistry laboratory. Cord bilirubin was done in all babies. Neonates were followed up daily for 5 days for hyperbilirubinemia. In neonates who developed significant jaundice, bilirubin estimation was done as required and treated with phototherapy as per Bhutani's normogram [8]. Serum bilirubin levels were estimated in all babies on day 5 . In the study, significant hyperbilirubinemia was defined as bilirubin $>15 \mathrm{mg} / \mathrm{dl}$ after 72 hours.

Statistical analysis: Data was entered in Microsoft excel sheetand analyzed using registered version of SPSS 20. Analysis was done using simple statistics like mean, median and proportions for general variables. Chi square test was done for finding the association between two or more categorical variables. The sensitivity, specificity positive predictive value and negative predictive value were calculated. The accuracy of the test was measured by using receiver operator curve.

\section{Results}

In the study 100 babies were enrolled. Clinically detectable jaundice was seen in $72 \%$. Twenty-two percent babies developed hyperbilirubinemia. Mean cord bilirubin was $2.8+2.4 \mathrm{mg} / \mathrm{dl}$ in those who developed hyperbilirubinemia and $2.5+2.91 \mathrm{mg} / \mathrm{dl}$ in those who did not. However, this was not statistically significant $(\mathrm{p}=0.62)$. Peak serum bilirubin of babies who developed significant hyperbilirubinemia was $23+2.8 \mathrm{mg} / \mathrm{dl}$ at 120 hours.

All the babies were exclusively breastfed. The baseline data is shown in table 1. There was no significant difference between the cases who did and who did not develop hyperbilirubinemia with respect to various factors such as gender, gestational age, birth weight, mode of delivery, use of oxytocin and pregnancy induced hypertension [Table 2]. However, ABO incompatibility was significantly associated with development of hyper bilirubinemia $(\mathrm{p}=0.0006)$ [Table 2].

Cord bilirubin level of $>2 \mathrm{mg} / \mathrm{dl}$ was present in 64 babies and 19 (29\%) developed hyperbilirubinemia. Cord bilirubin $<$ $2 \mathrm{mg}$ was present in 36 and only $3(8 \%)$ developed hyperbilirubinemia. This difference was statistically significant $(\mathrm{p}=0.018$ ) [Table 3]. Cord bilirubin $>2 \mathrm{mg} / \mathrm{dl}$ had sensitivity of $86 \%$, specificity of $40 \%$, positive predictive value of $29 \%$ and negative predictive value of $91 \%$. Odds of developing hyperbilirubinemia in babies with cord bilirubin $>2 \mathrm{mg} / \mathrm{dl}$ was 4.36 (95\% confidence interval 2.40,3.17). The accuracy of the test was measured using receiver operator curve [Figure 1]. The area under the curve was 0.755 which is deemed to be fair test results.

Table-1: Baseline characteristics of study population $(n=100)$.

\begin{tabular}{|c|c|}
\hline Characteristics & Number \\
\hline Female & $56(56 \%)$ \\
\hline Mean Gestational age(weeks) & $38.11+3.72 *$ \\
\hline Mean Birth weight(kg) & $2.98+3.26^{*}$ \\
\hline Delivery by Cesarean section & $64(64 \%)$ \\
\hline Normal vaginal delivery & $36(36 \%)$ \\
\hline Use of Oxytocin in mother & $44(44 \%)$ \\
\hline PIH(pregnancy induced hypertension) & $13(13 \%)$ \\
\hline History of Jaundice in previous sibling & $2(2 \%)$ \\
\hline ABO Incompatibility & $23(23 \%)$ \\
\hline
\end{tabular}

$(*=$ mean + standard deviation $)$ 
Original Research Article

Table-2: Characteristics of cases who did and who did not develop hyperbilirubinemia

\begin{tabular}{|c|c|c|c|}
\hline Characteristics & No Hyperbilirubinemia & $\begin{array}{c}\text { Hyperbilirubinemia } \\
\text { (n=22) }\end{array}$ & P value \\
\hline Male/Female & $33 / 45$ & $11 / 11$ & 0.5 \\
\hline Mean Gestational age(weeks) & $38.12+3.22^{*}$ & $38.11+4.22^{*}$ & 0.97 \\
\hline Mean Birth weight(kg) & $3.15+3.01^{*}$ & $2.81+3.52^{*}$ & 0.41 \\
\hline Type of delivery: Cesarean section & 48 & 16 & 0.10 \\
\hline Normal vaginal delivery & 30 & 6 & 0.11 \\
\hline Use of Oxytocin in mother & 35 & 9 & 0.51 \\
\hline Pregnancy induced hypertension & 10 & 3 & - \\
\hline History of Jaundice in previous sibling & - & 11 & 0.0006 \\
\hline ABO Incompatibility & 12 & 2 & \\
\hline
\end{tabular}

( $\mathrm{p}$ value $<0.05$ is significant, $*=$ mean + standard deviation)

Table- 3: Relationship of cord Bilirubin and Hyperblirubilirubinemia

\begin{tabular}{|c|c|c|c|c|}
\hline Cord Bilirubin & Hyperbilirubinemia & No Hyperbilirubinemia & Total & \multirow{2}{*}{ P Value } \\
\cline { 1 - 4 }$>\mathbf{2} \mathbf{~ m g / d l}$ & $19(29 \%)$ & $45(71 \%)$ & 64 & \multirow{2}{*}{0.018} \\
\hline$<\mathbf{2} \mathbf{~ m g / d l}$ & $3(8 \%)$ & $33(92 \%)$ & 36 & Significant \\
\hline Total & $22(22 \%)$ & $78(78 \%)$ & 100 & 6 \\
\cline { 1 - 4 }
\end{tabular}

( $\mathrm{p}$ value $<0.05$ is significant)

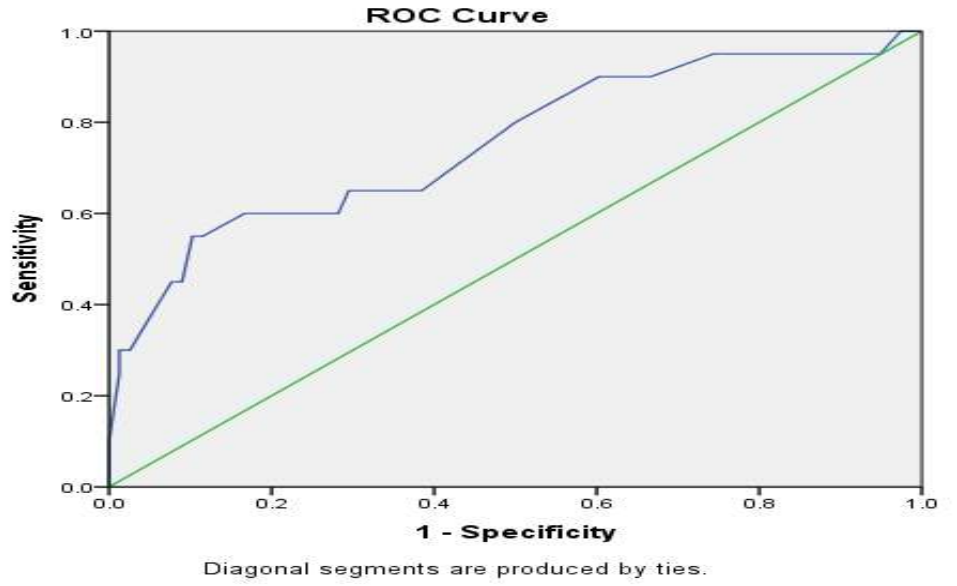

Figure-1: The receiver operating characteristics analysis of cord bilirubin level predicting the development of subsequent hyperbilirubinemia

\section{Discussion}

Neonatal jaundice is a benign condition observed during the first week of life.Hyperbilirubinemia in the newborn usually peaks between 3 and 7 days of age. This clinical condition is frequently asymptomatic and occurs after hospital discharge. It is worth noting that the most common cause for readmission during the early neonatal period is hyperbilirubinemia[10,11,12]. Higher cord bilirubin levels among infants who develop significant hyperbilirubinemia as compared to nonhyperbilirubinemic infants indicate that mechanisms of subsequent jaundice are already active in fetal life.Nearly all fetal bilirubin is unconjugated and in plasma is totally bound to albumin. The unconjugated bilirubin is transferred to maternal circulation by 
placenta for excretion [7]. The value of cord bilirubin for predicting significant hyperbilirubinemia is widely debated $[6,7,8,9]$. Many investigators have found cord bilirubin cut off values ranging $2-3.5 \mathrm{mg} / \mathrm{dl}$ to have good predictive value. $[7,8,13,14]$ However some others found cord serum bilirubin to have poor predictive value $[6,15,16]$.

In the present study, incidence of hyperbilirubinemia was $22 \%$ and clinically detectable jaundice was $72 \%$. Taksande et al [7] reported clinical jaundice in 56\% and hyperbilirubinemia in $19 \%$ where as Hamdi et al [17] reported $85 \%$ and $26 \%$ respectively of clinical jaundice and hyperbilirubinemia. Our observations were similar to Hamdi et al [17]. Other investigators have reported much lower incidence of $9.5 \%$ and $12.5 \%[1,18]$.

The present study was uniformly distributed with male to female ratio of 56:44. There was no significant association of gender with development of hyperbilirubinemia ( $\mathrm{p}$ 0.5). Other studieshave also reported similar findings $[1,7,8,17,19]$. In contrast Rudy et al study observed that there was significant difference in cord bilirubin between both sexes and this difference may be due to increased incidence of G6PD enzyme deficiency among males as it is $\mathrm{X}$ linked recessive disorder [20].

In the present study, gestational age, birth weight, maternal hypertension and mode of delivery did not have any significant association with development of hyperbilirubinemia.Similar observations were reported byother studies $[1,7,8,14,17,21,22]$.

We found significant association between $\mathrm{ABO}$ incompatibility and hyperbilirubinemia ( $p$ 0.0006). Earlier authors like Pradhan et al [1], Bernaldo et al[9] and Menon et al [23] also reported similar findings. Oxytocin use during labourwasnot associated with significant hyperbilirubinemia. This was similar to the study done by Taksande et al (7). In variance significant association between oxytocin use and hyper bilirubinemia was reported by Pradhan A, Nahar et al, Rajpurohit et al and Hamdi et al[1,8,14,17].

In the present study mean cord bilirubin value were 2.8 $+2.4 \mathrm{mg} / \mathrm{dl}$ in those who developed hyperbilirubinemia and $2.5+2.91 \mathrm{mg} / \mathrm{dl}$ in those who did not. However, this was not statistically significant $(\mathrm{p}=0.62)$. The studies by Pradhan et al, Rajpurohit et al and Farahat et al found that mean cord bilirubin value was significantly higher than those who developed as compared to those who did not. $[1,14,18]$
We observed that cord bilirubin $>2 \mathrm{mg} / \mathrm{dl}$ had the highest sensitivity $(86 \%)$. At this critical level specificity was $40 \%$, positive predictive value was $29 \%$ and negative predictive value was $91 \%$. ROC curve (figure 1) shows that area under curve (AUC) was 0.75 of the total area indicating the usefulness of test in predicting significant hyperbilirubinemia. Our findings are similar to Rajpurohitet al [14] study where the sensitivity was $90 \%$, specificity was $53 \%$, positive predictive value was $17.8 \%$ and negative predictive value $98 \%$ at critical bilirubin value $>2 \mathrm{mg} / \mathrm{dl}$.

Taksande etal [7] reportedhigh sensitivity (89\%) as well as high specificity (85\%), negative predictive value (98\%) and positive predictive value (38\%). Gatea etal also reported high negative predictive value of $98 \%$ but low positive predictive value $45.4 \%$ [24]. In contrast Rostami and Mehrabi found that cord bilirubin $>3$ $\mathrm{mg} / \mathrm{dl}$ is not a useful predictor and concluded that cord bilirubin cannot be used to predict subsequent hyperbilirubinemia [15].

Hemmati and Hashemi observed no significant relationship between cord bilirubin and development of hyperbilirubinemia but there was significant relation between predischarge bilirubin and development of hyperbilirubinemia.

Therefore, they concluded that bestpredictor for neonatal jaundice is assessment of clinical risk factors and predischarge bilirubin [25]

Our study had high negative predictive value which means that if cord bilirubin was $<2 \mathrm{mg} / \mathrm{dl}$ one could reasonably predict that the neonate would not develop hyperbilirubinemia. The ability of critical cord bilirubin value of $>2 \mathrm{mg} \%$ to discriminate between those who developed and those who did not develop hyperbilirubinemia was fair as depicted by area under curve $(0.75)$

\section{Conclusions}

Mean cord bilirubin was higher in those who developed hyperbilirubinemia although this difference was not statistically significant. Cord serum bilirubin $>2 \mathrm{mg} / \mathrm{dl}$ had high sensitivity and negative predictive value but low specificity and positive predictive value. Our findings suggest that cord bilirubin may be useful in identifying neonates who develop significant hyperbilirubinemia. Neonates with cord bilirubin $<2 \mathrm{mg} / \mathrm{dl}$ are probably safe for early discharge but those with bilirubin levels $>2 \mathrm{mg} / \mathrm{dl}$ will need close follow up. What is already known? 
Theassociation between cord bilirubin levels and subsequent hyperbilirubinemia.

Acknowledgement: Alka Gore for assistance [statistical department]

What this study adds?: Cord bilirubin is a fairly good predictor for hyperbilirubinemia.

\section{Contributors}

GR: Data collection, statistical analysis, literature search and manuscript preparation. SD: Study concept and critical revision of manuscript

Funding: Nil, Conflict of interest: None initiated, Perission from IRB: Yes

\section{References}

1. Pradhan A, Lamichaney R, Sharma V. Cord blood bilirubin level as a predictor of development of pathological hyper bilirubinemia in new-borns. Int $\mathrm{J}$ Contemp Pediatric 2017;4:1519-24 DOI: http:/dx.doi. org/10. 18203/2349-3291. ijcp20172698.

2. Bhutani VK, Johnson-Hamerman L. The clinical syndrome of bilirubin-induced neurologic dysfunction. Semin Fetal Neonatal Med. 2015 Feb;20(1):6-13. doi: 10.1016/j.siny.2014.12.008. Epub 2015 Jan 7.

3. American Academy of Pediatrics Subcommittee hyper bilirubinaemia (2004) Management of hyper bilirubinaemia in the newborn infant 35 or more week of gestation. Pediatrics 2004: 114(1): 297-316. DOI: 10. 1542/peds.114.1.297.

4. Le LT, Partridge JC, Tran BH, Le VT, Duong TK, Nguyen HT, Newman TB. Care practices and traditional beliefs related to neonatal jaundice in northern Vietnam: a population-based, cross-sectional descriptive study. BMC Pediatr. 2014 Oct 14;14:264. doi: 10.1186/1471-2431-14-264.

5. Habib HS. Impact of discharge timings of healthy newborns on the rates and etiology of neonatal hospital readmissions. J Coll Physicians Surg Pak. 2013 Oct; 23 (10):715-9. doi: 10.2013/JCPSP.715719.

6. Vasudevan J, Reddy GMM, Thayumanavan S. 2013. Use fulness of cord bilirubin as a screening test to predict newborns at risk of hyper bilirubinemia. Pediatric Oncall. 2013;10(9). DOI: 10.7199/ped. oncall. 50. (Sep)
7. Taksande Amar, Vihekar Krishna, Manish, et al. Prediction of the development of neonatal hyper bilirubinemia by increased umbilical cord blood bilirubin. Indmedica Curr Pediatric Res 2005; 9 (1) :1-9.

8. Nahar Z, Shahidullah MD, Mannan A, Dey SK, Mitra U, Selimuzzaman SM. The value of umbilical cord blood bilirubin measurement in predicting the development of significant hyper bilirubinemia in healthy Newborn. Bangladesh J Child Health. 2009;33 (2): 50-4.

9.BernaldoAJ, Segre CA.Bilirubin dosage in cordblood: could it predict neonatal hyperbilirubinemia? Sao Paulo Med J. 2004 May 6;122(3):99-103. Epub 2004 Sep 16.

10. Bhutani VK, Gourley GR, Adler S, Kreamer B, Dalin C, Johnson LH. Noninvasive measurement of total serum bilirubin ina multiracial predischarge new bornpopulation to assess the risk of severe hyper bilirubinemia. Pediatrics. 2000 Aug;106(2):E17.

11. Lock M, Ray JG. Higher neonatal morbidity after routine early hospital discharge: Are we sending newborns home too early? Can Med Assoc J 1999;161 (3): 249 .

12. Chary E, Bharadwaj N, Kumar P, Vivekand N, Sailaja V, Harika B. Umbilical Cord Blood Bilirubin Level Measurement in Predicting the Development of Significant Hyper bilirubinemia. Indian Journal of Mednodent and Allied Sciences. 2014; 2(2):144. DOI : 10. 5958/2347-6206.2014.00003.X

13. Ahire N, SonawaneR,Gaikwad R, Patil S Study of Correlation of Cord Blood Bilirubin with Neonatal Hyperbilirubinemia. MVPJOM 2016; 3(1): DOI:10. 18311 / mvpjms/2016/v3i1/739

14. Rajpurohit N, Kumar S, Sharma D, Choudhary M, Purohit S (2015) To Assess Predictive Value of Cord Blood Bilirubin and Albumin for Significant Neonatal Hyperbilirubinemia: A Prospective Study from India. J Pediatric Neonatal Care 2015; 2(1): 00060. DOI: 10. 15406 /jpnc.2015.02.00060

15. Rostami N, MehrabiYadElah, Asadzadeh F. Identifying the newborns at risk for developing significant hyper bilirubinemia by measuring cord bilirubin levels. Pejouhandeh. 2005; 9(6):365-9. 
16.JacobsonMP, BernsteinHH.Limited diagnostic value of routine cord blood bilirubin determinations. Clin Peiatr (Phila). 1982 Oct;21(10): 610-2.

17. Hamdi N, Elgayar A,Sallah H. Cord Blood Bilirubin as a Predictor of Neonatal Hyper bilirubinemia. Med. J. Cairo Univ. 2012; Vol. 80, No. 2, June: 31-36.

18. Farhat R, Rajab M. Length of postnatal hospital stay in healthy newborns and re-hospitalization following early discharge. N Am J Med Sci. 2011 Mar;3(3):14651. doi: 10.4297/najms.2011.3146.

19. Zeitoun A, AlaaEldin\& F. Elhagrasy, Hala\& M. Abdelsatar, Doaa. Predictive value of umbilical cord blood bilirubin in neonatal hyperbilirubinemia. Egyptian Pediatric Association Gazette. 2013;61. (23). doi: 10.1016/j.epag.2013.04.006.

20. Satrya Rudy, Effendi Sjarif H, Gurnida Dida A. Correlation between cord blood bilirubin level and incidence of hyperbilirubinemia in term newborns. Paediatr Indones2009;6:349-54.doi: https://oi.org/10. 14238/pi49.6.2009.349-54.
21. Awasthi S, Rehman H. Early prediction of neonatal hyperbilirubinemia. Indian J Pediatr. 1998 Jan-Feb; 65 (1): 131-9.

22. Knudsen A. Prediction of the development of neonatal jaundice by increased umbilical cord blood bilirubin. Acta Paediatr Scand. 1989 Mar; 78(2):217-21.

23. Maya Menon, Sreejyothi G, Raveendranath K, Incidence of early neonatal hyper bilirubinemia in $\mathrm{ABO}$ incompatibility and cord bilirubin as a predictor for phototherapy: Int J Pediatric Res 2016;3(4):218-224. doi: 10. 17511/ijpr.2016.4.02.

24. Gatea SK. Cord bilirubin level as predictor for newborns at risk for post natal hyperbilirubinemia. Kufa Med Journal. 2009; 12: 109-117.

25. Hemmati, F., Hashemi, Z. Evaluation of the Predictive Value of Umbilical Cord Serum Bilirubin Level for the Development of Subsequent Hyper bilirubinemia in Term and Late-Preterm Neonates. Iranian Journal of Neonatology IJN, 2016; 7(1): 25-31. doi: 10.22038/ijn.2016.6661.

\section{How to cite this article?}

Rajput G, Dhanawade S. Cord bilirubin as a Predictor of Neonatal Hyper bilirubinemia in healthy term babies. Int J Pediatr Res. 2018;5(4):243-248.doi:10.17511/ijpr.2018.i04.14. 